Article

\title{
Increased Consumption of Sulfur Amino Acids by Both Sows and Piglets Enhances the Ability of the Progeny to Adverse Effects Induced by Lipopolysaccharide
}

\author{
Ying Zhang ${ }^{1,2}$, Bao-Yang Xu ${ }^{1}$, Ling Zhao ${ }^{1}$, Luo-Yi Zhu ${ }^{1}$, Dolores Batonon-Alavo ${ }^{3}$, \\ Jeremy Jachacz ${ }^{3}$, De-Sheng Qi ${ }^{1}$, Shu-Jun Zhang ${ }^{2}$, Li-Bao Ma ${ }^{1, *}$ and Lv-Hui Sun ${ }^{1, *}$ \\ 1 Department of Animal Nutrition and Feed Science, College of Animal Science and Technology, Huazhong \\ Agricultural University, Wuhan 430070, China; zhangysunny@163.com (Y.Z.); baoyangxu@126.com (B.-Y.X.); \\ lingzhao@webmail.hzau.edu.cn (L.Z.); zhuluoyi@outlook.com (L.-Y.Z.); qds@mail.hzau.edu.cn (D.-S.Q.) \\ 2 Key Lab of Breeding and Reproduction of Ministry of Education, Huazhong Agricultural University, \\ Wuhan 430070, China; sjxiaozhang@mail.hzau.edu.cn \\ 3 Adisseo France S.A.S., 10, Place du Général de Gaulle, 92160 Antony, France; \\ dolores.batonon-alavo@adisseo.com (D.B.-A.); jeremy.jachacz@inra.fr (J.J.) \\ * Correspondence: malibao@126.com (L.-B.M.); lvhuisun@mail.hzau.edu.cn (L.-H.S.)
}

Received: 23 October 2019; Accepted: 20 November 2019; Published: 29 November 2019

Simple Summary: Our results suggest that maternal consumption of total sulfur amino acids exceeding the NRC 2012 recommendations by $25 \%$ during late gestation and lactation benefits sow productivity and piglet neonatal performance. Moreover, increased consumption of sulfur amino acids by both sows and post-weaned piglets improved their ability to counteract the adverse effects by lipopolysaccharide (LPS) exposure. In addition, OH-Met showed a better response than DL-Met in both neonatal and weaned piglets. Taken together, our findings indicate that it might be necessary to update the recommendations for sulfur amino acids for gestating and lactating sows. Attention should also be given to sulfur amino acids supply during an inflammatory challenge as often encountered by piglets early in life.

Abstract: This study determined the effects of increased consumption of sulfur amino acids (SAA), as either DL-Met or Hydroxy-Met (OH-Met), by sows and piglets on their performance and the ability of the progeny to resist a lipopolysaccharide (LPS) challenge. Thirty primiparous sows were fed a diet adequate in SAA (CON) or CON $+25 \%$ SAA, either as DL-Met or OH-Met from gestation day 85 to postnatal day 21 . At $35 \mathrm{~d}$ old, 20 male piglets from each treatment were selected and divided into 2 groups ( $n=10$ /treatment) for a $3 \times 2$ factorial design [diets (CON, DL-Met or OH-Met) and challenge (saline or LPS)]. OH-Met and/or DL-Met supplementation increased $(p \leq 0.05)$ piglets' body weight gain during day $0-7$ and day 7-14. Sow's milk quality was improved in the supplemented treatments compared to the CON. The LPS challenge decreased $(p \leq 0.05)$ piglets' performance from 35 to $63 \mathrm{~d}$ and increased $(p \leq 0.05)$ the levels of aspartate aminotransferase, total bilirubin, IL-1 $\beta$, IL-6, TNF-a, and malondialdehyde. Plasma albumin, total protein, total antioxidant capacity and glutathione peroxidase decreased post-challenge. The results were better with OH-Met than DL-Met. The increase of Met consumption, particularly as $\mathrm{OH}-\mathrm{Met}$ increased piglets' growth performance during the lactation phase and the challenging period.

Keywords: sows; piglets; methionine; lipopolysaccharide; performance 


\section{Introduction}

Livestock husbandry practices have prompted an expanded use of synthetic amino acids in animal diets to enhance the performance and carcass quality of livestock, as well as to minimize the environmental impact caused by nitrogen excretion [1-4]. This is true for methionine, which is an essential amino acid for all livestock species, and it is the first limiting amino acid in diets for poultry and the second or third limiting amino acid in the corn-soybean meal diets for pigs $[5,6]$. Methionine is not only used for protein synthesis, but it is also involved in the methylation reactions of DNA $[7,8]$ and in choline metabolism $[9,10]$. Methionine plays a role in antioxidant defense and acts as the precursor for bioactive compounds such as glutathione (GSH) and taurine [11,12].

Conventional sources of supplemental methionine used in animal feeds are either DL-methionine (DL-Met) or 2-hydroxy-4-methylthiobutanoic acid (OH-Met) [13]. Although these two compounds both provide L-methionine to various animal species, they are chemically different; OH-Met has a hydroxyl group at the asymmetric carbon atom, whereas DL-Met has an amino group. This chemical difference results in numerous differences with respect to the chemistry, absorption, transport in the body and metabolism by tissues [13]. Indeed, DL-Met is absorbed by active transport, whereas, OH-Met was absorbed by both active transport (Monocarboxylate transporter 1) and passive diffusion [14]. A previous study showed that increased consumption of methionine as $\mathrm{OH}-\mathrm{Met}$ increased milk fat, lactose, cysteine, and taurine concentrations in OH-Met diet-fed sows [15]. The body weight of suckling piglets at two weeks of age in the OH-Met group was higher than that of the control group and tended to be higher than that of the DL-Met group [16]. However, there is a lack of studies for sows during late gestation regarding the efficacy of OH-Met as a source of methionine relative to DL-Met.

In addition, weaning, when performed at very young age, is a period of physiological stress for piglets that predisposes them to enteric disease caused by pathogens such as Escherichia coli 0149 [17]. During E. coli infection, the bacterial endotoxin lipopolysaccharide (LPS) activates cells of the innate immune system leading to inflammation. Prolonged and/or excessive inflammation caused by stimulants such as LPS can adversely affect animal productivity by inducing muscle catabolism, anorexia and oxidative stress that is damaging to various organs [18]. According to previous reports, the demand for sulfur amino acids (SAAs), most notably cysteine, increases during immune responses $[19,20]$. Methionine is a precursor of cysteine and a potent antioxidant and immunity regulator [21,22]. Also, supplementing sow diets with extra methionine above the recommendations during gestation and lactation may provide additional methionine to piglets via the placenta and milk. Therefore, we hypothesized that supplementing methionine above the recommendations in the diets of sows during gestation and lactation could help their progeny counteract the adverse effects of oxidative stress and inflammation induced by LPS. In addition, with regards to the previous studies $[15,16]$, we hypothesized that the better transulfuration obtained with OH-Met could lead to better results in comparison to DL-Met.

This study first aimed to compare the effects of an increase in dietary methionine as OH-Met or DL-Met on the performance of sows and their progeny during gestation and lactation. The second objective of this study was to assess the effects of LPS-induced inflammation and oxidative stress on piglets' responses when they were fed increased levels of total SAAs, through either DL-Met or OH-Met diets, for a prolonged period of time during the post-weaning period.

\section{Materials and Methods}

\subsection{Animals, Treatments and Sample Collection}

Our animal protocol was approved by the Institutional Animal Care and Use Committee of Huazhong Agricultural University, China (ethical approval code (if they do not have the code but you saved the file they sent to you, it is also fine to leave it like this)). In total, 30 primiparous sows (Landrace $\times$ Yorkshire) were randomly allocated to three treatment groups ( $n=10$ pens/treatment, 1 sow/pen) on gestation d 85 based on their body weight and backfat thickness (Supplemental Figure S1). Each sow 
was housed in a gestation crate from day 85 to 110 then in farrowing crate from day 110 of gestation to day 21 of lactation. Sows during gestation were allowed free access to water and mash feed; Sows were fed $1.0 \mathrm{~kg}$ feed at the first day of lactation, and feed was increased by $1.0 \mathrm{~kg}$ every day until day 7 of lactation. Free access to feed was given from 8 to 21 days of lactation. The control group of sows was fed a corn/soybean-control diet (CON) formulated to meet the nutritional requirements of sows (NRC, 2012, Table 1). The other two groups of sows were fed the control diet supplemented with either DL-Met (Rhodimet NP99 Adisseo, Antony, France) or OH-Met (Rhodimet AT88 Adisseo, Antony, France) at 25\% above the total SAAs present in the control diet. The dose was chosen based on previous studies that reported that a dietary supplementation of an additional $25 \%$ total SAAs (TSAAs) during lactation improved the milk quality of sows and the antioxidant capacity of their progeny $[15,16]$. Within $12 \mathrm{~h}$ of farrowing, all litters were standardized to have 10 piglets per sow according to the average body weight of the piglets. Body weight and feed intake data of sows and their progeny were measured by a weighbridge during gestation and lactation. The backfat thickness of sows was measured $65 \mathrm{~mm}$ from the left side of the dorsal midline at the last rib level (P2) using an ultrasound (Lean-Meater, Renco, MN, USA) [16]. Blood was collected from the anterior vena cava of sows and piglets that were feed-deprived overnight for $8 \mathrm{~h}$ on gestation $\mathrm{d} 85$ and lactation $\mathrm{d} 0$ and 14 . The plasma was prepared by centrifugation in heparinized tubes at $1000 \times \mathrm{g}$ for $15 \mathrm{~min}$ at $4{ }^{\circ} \mathrm{C}$ and stored at $-80^{\circ} \mathrm{C}$ [22]. Colostrum was collected from each sow within $4 \mathrm{~h}$ of farrowing of the first piglet; milk was also collected from each sow after being feed-deprived overnight for $8 \mathrm{~h}$ on lactation day 14, as described previously [16]; the milk was stored at $-80^{\circ} \mathrm{C}$ before use.

On day 21, piglets were weaned, and piglets from the same sow were kept in a pen (Supplemental Figure S1). Piglets were not castrated. Piglets from the CON group of sows were fed antibiotic-free control diet (CON) formulated to meet their nutritional requirements (NRC, 2012, Table 1). Piglets from the DL-Met or OH-Met groups of sows were fed the CON supplemented with either DL-Met (DL-Met) or OH-Met (OH-Met) at 25\% above the total SAAs present in the CON. The body weight of piglets was measured by a weighbridge at day 21 and 35. Piglets were allowed free access to the mash feed and water. Feed intake was measured for the 21-35 d period.

On the morning of day 35, 60 male piglets from the three dietary treatments (20 piglets/treatment) were selected according to their body weight (Supplemental Figure S1). The initial body weights of the piglets were standardized and did not significantly differ among the 6 groups. They were divided into 6 groups ( $n=10$ /group) for a $3 \times 2$ factorial design trial that included the dietary treatments (CON, DL-Met and OH-Met) and immunological challenge (saline vs. LPS (100 $\mu \mathrm{g} / \mathrm{kg}$ BW, E. coli 0111: B4, Sigma)) by intraperitoneal injection. The dose of LPS was chosen in accordance with previous studies [23]. Blood was obtained from all piglets at $0 \mathrm{~h}$ pre-challenge and 4,12 , and $24 \mathrm{~h}$ post challenge to assess the acute phase response. Then, the piglets from the 6 groups ( $n=5$ pens/groups, 2 piglets/pen) were allowed free access to the same mash diets as before the immunological challenge for 4 weeks. The body weight and feed intake were measured biweekly from day 35 to day 63 . 
Table 1. Ingredients and nutrients composition of the Control diet offered to both sows and piglets ${ }^{1}$.

\begin{tabular}{|c|c|c|c|c|}
\hline \multirow{2}{*}{ Ingredients (\%) } & \multicolumn{2}{|c|}{ Sows } & \multicolumn{2}{|c|}{ Piglets } \\
\hline & Gestation & Lactation & $\begin{array}{l}\text { Post-Weaning I } \\
\text { (21-35 d Old) }\end{array}$ & $\begin{array}{l}\text { Post-Weaning II } \\
\text { (35-63 d Old) }\end{array}$ \\
\hline Corn & 61.77 & 65.74 & 17.60 & 60.70 \\
\hline Expanded corn & - & - & 15.0 & - \\
\hline Wheat flour & - & - & 10.0 & - \\
\hline Wheat bran & 15 & - & - & - \\
\hline Soybean meal & 14 & 28 & - & 27.5 \\
\hline Expanded soybeans & - & - & 8.0 & - \\
\hline Fermented soybean meal & - & - & 5.0 & - \\
\hline Corn gluten feed & 2.0 & - & - & - \\
\hline Fish meal & - & - & 4.0 & 5.0 \\
\hline Whey powder & - & - & 12.0 & - \\
\hline Soybean oil & 3.5 & 2.5 & - & 2.5 \\
\hline Sugar & - & - & 8.0 & - \\
\hline Glucose & - & - & 6.0 & - \\
\hline Emulsified fat powder & - & - & 5.0 & - \\
\hline Plasma protein & - & - & 5.0 & - \\
\hline $\mathrm{CaCO}_{3}$ & 1.00 & 0.60 & 0.50 & 0.50 \\
\hline $\mathrm{CaHPO}_{4}$ & 1.20 & 1.70 & 1.50 & 1.50 \\
\hline Salt & 0.30 & 0.30 & 0.30 & 0.30 \\
\hline DL-Met & 0.07 & 0.06 & 0.30 & 0.25 \\
\hline L-Lys & 0.16 & 0.10 & 0.50 & 0.55 \\
\hline L-Thr & - & - & 0.30 & 0.20 \\
\hline Vitamin premix ${ }^{2}$ & 0.50 & 0.50 & 0.50 & 0.50 \\
\hline Mineral premix ${ }^{3}$ & 0.50 & 0.50 & 0.50 & 0.50 \\
\hline Crude protein (\%) & 14.6 & 17.6 & 21.0 & 20.9 \\
\hline Digestible energy $(\mathrm{MJ} / \mathrm{kg})$ & 13.7 & 14.2 & 14.2 & 14.0 \\
\hline Total Lys (\%) & 0.75 & 0.98 & 1.45 & 1.56 \\
\hline Total Met (\%) & 0.29 & 0.32 & 0.48 & 0.58 \\
\hline Total Met + Cys (\%) & 0.52 & 0.60 & 0.82 & 0.88 \\
\hline D Lys (\%) & 0.65 & 0.85 & 1.30 & 1.40 \\
\hline SID Met (\%) & 0.26 & 0.28 & 0.45 & 0.53 \\
\hline SID Met+Cys (\%) & 0.45 & 0.52 & 0.72 & 0.78 \\
\hline Calcium $(\%)$ & 0.69 & 0.69 & 0.65 & 0.81 \\
\hline Total phosphorus (\%) & 0.60 & 0.63 & 0.64 & 0.73 \\
\hline
\end{tabular}

${ }^{1}$ The DL-Met and OH-Met treatment diets during gestation, lactation, and day 21-35 and day 35-63 were prepared by adding $1.313,1.515,2.071$, or $2.22 \mathrm{~kg}$ DL-Met $(99 \%)$ and $1.477,1.705,2.330$, or $2.5 \mathrm{~kg} \mathrm{OH}-$ Met $(88 \%)$, respectively, to $1000 \mathrm{~kg}$ of the control diet at the expense of corn. These methionine sources addition leading to obtain TSSA levels in DL-Met and OH-Met treatments for gestation, lactation, and day $21-35$ and day $35-63$ are $0.65 \% ; 0.65 \% ; 1.04 \%$; $1.00 \%$, respectively. ${ }^{2}$ Vitamin premix provided per kg of diet: retinyl acetate, $10000 \mathrm{IU}$; cholecalciferol $2500 \mathrm{IU}$; dl- $\alpha$-tocopheryl acetate, $50 \mathrm{IU}$; menadione, $5.0 \mathrm{mg}$; thiamin, $2.0 \mathrm{mg}$; riboflavin, $5.0 \mathrm{mg}$; pantothenic acid, $12.0 \mathrm{mg}$; pyridoxine, $10.0 \mathrm{mg}$; niacin, $30.0 \mathrm{mg}$; $d$-biotin, $0.2 \mathrm{mg}$; folic acid, $1.5 \mathrm{mg}$; cyanocobalamin, $0.05 \mathrm{mg}$; choline chloride $1500 \mathrm{mg}$. ${ }^{3}$ Mineral premix provided per kg of diet: $\mathrm{FeSO}_{4} \bullet 7 \mathrm{H}_{2} \mathrm{O}, 498 \mathrm{mg} ; \mathrm{CuSO}_{4} \bullet 5 \mathrm{H}_{2} \mathrm{O}, 78.7 \mathrm{mg} ; \mathrm{MnSO}_{4} \bullet 5 \mathrm{H}_{2} \mathrm{O}$, $110 \mathrm{mg} ; \mathrm{ZnSO}_{4} \bullet 7 \mathrm{H}_{2} \mathrm{O}, 440 \mathrm{mg} ; \mathrm{Na}_{2} \mathrm{SeO}_{3}, 0.66 \mathrm{mg} ; \mathrm{KI}, 0.4 \mathrm{mg}$.

\subsection{Milk Composition and Amino Acid Analysis}

The concentrations of fat, lactose, protein, and nonfat solid in milk were analyzed using an ultrasonic milk analyzer (MILKYWAY-CP2; Hangzhou Simple Technology Company, Limited, Hangzhou, China) as described previously [15]. The free amino acid concentration in milk was measured, as described previously [24]. Briefly, $1.0 \mathrm{~mL}$ milk was mixed with $1.0 \mathrm{~mL}$-hexane and centrifuged at $12,000 \times \mathrm{g}$ for $5 \mathrm{~min}$ at $4{ }^{\circ} \mathrm{C}$ to remove fat. Then, $1.0 \mathrm{~mL}$ of the lower layer liquid was thoroughly mixed with $1.0 \mathrm{~mL} \mathrm{5.0 \%}$ sulfosalicylic acid and centrifuged at $12,000 \times \mathrm{g}$ for $15 \mathrm{~min}$ at $4{ }^{\circ} \mathrm{C}$ to remove proteins. Finally, the supernatant was collected and filtered using a $0.22 \mu \mathrm{m}$ millipore filter for free amino acid analysis using the Sykam S-433D automatic amino acid analyzer according to the ninhydrin postcolumn derivatization method. 


\subsection{Plasma Biochemical and Antioxidant Parameter Analysis}

The concentrations of interleukin-1 beta (IL-1 $\beta$ ), interleukin-6 (IL-6) and tumor necrosis factor-a (TNF-a) in plasma were measured using an ELISA kit with catalog numbers PLB00B, P6000B, and PTA00 from R\&D Systems (USA). The concentrations of total protein (TP), albumin (ALB) and total bilirubin (TBIL) and activities of alanine aminotransferase (ALT) and aspartate aminotransferase (AST) were measured using a colorimetric method with specific assay kits (A045-2, A028-1, C019-1, C009-2 and C010-2) from the Nanjing Jiancheng Bioengineering Institute of China $[25,26]$. The activities of glutathione peroxidase (GPX) and total antioxidant capacity (T-AOC) and concentrations of GSH, glutathione disulfide (GSSG) and malondialdehyde (MDA) were measured using a colorimetric method with specific assay kits (A005, A015-1, A006-1, A061-2, and A003-1) from the Nanjing Jiancheng Bioengineering Institute of China [27].

\subsection{Statistical Analyses of Results}

Statistical analysis was performed using XLSTAT (Version 2015.3.01.19199). Growth performance data, backfat thickness and litter size generated from the sows and progeny during the lactation period were analyzed by one-way ANOVA using the Equation (1).

$$
Y_{i j}=\propto+\beta X_{i}+\varepsilon_{i j}
$$

where $Y_{i j}=$ the response variable for treatment $i, X_{i}=$ treatment effect $(i=$ CON, DL-Met, OH-Met $), j$ being the experimental unit number, $\varepsilon_{i j}=$ residual of the model.

An ANCOVA model was applied to body weight data generated during the LPS challenge, taking the treatments (CON, DL-Met, OH-Met) and the challenge (saline vs. LPS) as qualitative variables and the body weight at $\mathrm{d} 35$ as a quantitative variable, according to Equation (2):

$$
Y_{i j k}=\propto+\beta X_{i}+\delta Z_{j}+B W_{k}+\theta X Z_{i j}+\varepsilon_{i j k}
$$

where $Y_{i j k}=$ the response variable for treatment $i$, challenge $j$ and the initial body weight $k ; X_{i}=$ treatment effect ( $i=\mathrm{CON}$, DL-Met, OH-Met), $Z_{j}=$ challenge effect ( $j=$ LPS, Saline); $B W_{k}=$ the body weight for the $k$ th individual at 35 days old; $X Z_{i j}$ is the interaction between the treatment and the challenge, $\varepsilon_{i j k}=$ residual of the model.

The growth performance data and biochemistry data generated during the challenge were submitted to a two-way ANOVA using the following model described in Equation (3):

$$
Y_{i j}=\propto+\beta X_{i}+\delta Z_{j}+\theta X Z_{i j}+\varepsilon_{i j}
$$

where $Y_{i j k}=$ the response variable for treatment $i$, challenge $j ; X_{i}=$ treatment effect $(i=$ CON, DL-Met, OH-Met), $Z_{j}=$ challenge effect ( $j=$ LPS, Saline; $X Z_{i j}$ is the interaction between the treatment and the challenge, $\varepsilon_{i j}=$ residual of the model.

$p \leq 0.05$ was considered significant, and $p \leq 0.10$ was considered to have a tendency toward difference. If there was a significant effect, a Tukey test was used for post hoc comparisons of means. Results were presented as means with SEM.

\section{Results}

\subsection{Performance of Sows and Piglets during the Late Gestation Phase, throughout the Lactation Phase and} Day 21 to 35

Table 2 presents the performance of the sows during the gestation and lactation periods. No significant differences $(p>0.05)$ were found in body weight and backfat thickness of the sows among the three groups at lactation $\mathrm{d} 0$ and $\mathrm{d} 21$. However, sow body weight loss between lactation $\mathrm{d} 0$ and d 21 tended to be reduced with OH-Met $(p=0.08)$ compared to CON, whereas a significant effect 
of OH-Met was observed on the loss in back fat thickness $(p \leq 0.05)$. The average daily feed intake was not affected by dietary treatments from gestation d 85 to gestation d 114 and from d 0 to d 21 of lactation. Litter size at birth was not different among the treatments.

Table 2. Performance of sows fed with diets supplemented with either DL-Methionine (DL-Met) or DL-2-hydroxy-4-methylthiobutanoic acid (OH-Met) at the requirements in TSAAs or above during the late gestation and lactation periods and their progeny ${ }^{1}$.

\begin{tabular}{|c|c|c|c|c|c|}
\hline Item & CON & DL-Met & OH-Met & SEM & $p$-Value \\
\hline Sows (No. of sows) & 10 & 10 & 10 & & \\
\hline \multicolumn{6}{|l|}{ Body weight, kg } \\
\hline Gestation day 85 & 174 & 172 & 170 & 4 & 0.720 \\
\hline Lactation day 0 & 179 & 174 & 171 & 4 & 0.337 \\
\hline Lactation day 21 & 173 & 170 & 171 & 5 & 0.879 \\
\hline Changes (Lactation day 0-21) & $-6.29 *$ & -4.25 & $-0.33 *$ & 0.24 & 0.235 \\
\hline \multicolumn{6}{|l|}{ Backfat thickness, $\mathrm{mm}$} \\
\hline Gestation day 85 & 17.4 & 18.3 & 17.7 & 0.9 & 0.800 \\
\hline Lactation day 0 & 18.5 & 19.5 & 19.0 & 1.0 & 0.766 \\
\hline Lactation day 21 & 16.5 & 17.9 & 18.4 & 0.9 & 0.349 \\
\hline Changes (Lactation day 0-21) & $-2.00^{\dagger}$ & -1.61 & $-0.61^{\dagger}$ & 0.41 & 0.068 \\
\hline \multicolumn{6}{|l|}{ Average daily feed intake, $\mathrm{kg}$} \\
\hline Gestation day 85-114 & 3.12 & 3.17 & 2.97 & 0.18 & 0.731 \\
\hline Lactation day $0-21$ & 5.26 & 5.32 & 5.26 & 0.11 & 0.913 \\
\hline \multicolumn{6}{|l|}{ Litter size at birth } \\
\hline Born alive, $\mathrm{n}$ & 11.5 & 11.1 & 10.6 & 0.8 & 0.374 \\
\hline Stillborn,\% & 6.40 & 1.91 & 3.87 & 1.47 & 0.317 \\
\hline Mummies, $\%$ & 0.00 & 0.00 & 0.83 & 0.28 & 0.381 \\
\hline \multicolumn{6}{|l|}{ Piglet's body weight, $\mathrm{kg}$} \\
\hline Body weight at day 0 & 1.33 & 1.19 & 1.30 & 0.06 & 0.296 \\
\hline Body weight gain day $0-7, \mathrm{~kg}$ & $0.68^{\#}$ & 0.82 & $1.01^{\#}$ & 0.08 & 0.207 \\
\hline Body weight gain day $7-14, \mathrm{~kg}$ & $1.03^{\mathrm{a}}$ & $1.60^{b}$ & $1.68^{\mathrm{b}}$ & 0.09 & 0.009 \\
\hline Body weight gain day $14-21, \mathrm{~kg}$ & 1.89 & 1.66 & 1.66 & 0.09 & 0.961 \\
\hline Piglet's Mortality day $0-21, \mathrm{n}$ & 1.65 & 1.01 & 2.47 & 0.88 & 0.530 \\
\hline \multicolumn{6}{|l|}{ Post-weaning phase (day $21-35)^{2}$} \\
\hline Body weight day $35, \mathrm{~kg}$ & $7.66^{+}$ & 8.25 & $8.47^{+}$ & 0.30 & 0.175 \\
\hline Body weight gain, $\mathrm{kg}$ & 2.76 & 2.82 & 2.87 & 0.08 & 0.861 \\
\hline Feed intake day $35, \mathrm{~kg}$ & 3.35 & 3.36 & 3.40 & 0.14 & 0.956 \\
\hline Feed conversion ratio day $21-35, \mathrm{~kg} / \mathrm{kg}$ & 1.22 & 1.20 & 1.19 & 0.04 & 0.841 \\
\hline
\end{tabular}

${ }^{1}$ Values are means \pm SE, $n=10$. Labeled means in a row with unlike superscript letters were significantly different by Tukey test $(p<0.05) .{ }^{*},+, \#,+$ Different by Tukey test: ${ }^{*} p=0.10 ;{ }^{\dagger} p=0.03 ;{ }^{\#} p=0.10 ;{ }^{+} p=0.09$. CON = control diet; DL-Met $=$ CON supplemented with DL-Met at $25 \%$ above the total sulphur amino acids present in the control diet; $\mathrm{OH}-\mathrm{Met}=\mathrm{CON}$ supplemented with $\mathrm{OH}-\mathrm{Met}$ at $25 \%$ above the total sulphur amino acids present in the control diet. ${ }^{2}$ Piglets were weaned at $21 \mathrm{~d}$. They were fed with post-weaning diets according to their maternal feeding until day 35 .

The piglets' body weights at birth was not significantly different between the three treatments (Table 2). However, during lactation day 0-7, OH-Met increased the body weight gain of piglets $(p=0.10)$ by $62 \%$ in comparison to the CON. During lactation day $7-14$, in comparison to the CON, DL-Met resulted in a 55\% increase in piglet body weight gain, whereas OH-Met treatment resulted in a $63 \%$ increase. No significant effect of the treatments was observed on piglet mortality during the lactation period. At $35 \mathrm{~d}$ old, after two weeks of post-weaning feed supply, the piglets' body weight, feed intake and feed conversion ratio were not significantly different between treatments. However, $\mathrm{OH}-$ Met tended $(p=0.09)$ to increase body weight in comparison to the CON (Table 2).

\section{Milk Composition and Free Amino Acid Concentrations}

Milk composition at lactation d 0 and d 14 is presented in Table 3. The supplemented treatments tended to increase milk protein $(p=0.07)$ and lactose $(p=0.09)$ concentrations on lactation d 0 . Nonfat solid content was significantly increased $(p \leq 0.05)$ with both DL-Met and OH-Met, in comparison to the CON. On lactation day 14, milk fat content was similar between treatments. Milk protein concentration was significantly increase with $\mathrm{OH}-\mathrm{Met}$ supplementation $(5.64 \pm 0.34 \%)$ in comparison to the CON $(4.48 \pm 0.23 \%)$, while DL-Met led to intermediate results $(5.22 \pm 0.52 \%)$. Lactose and nonfat 
solids were significantly increased with the increasing HO-methionine level but not with DL-Met in comparison to control.

Table 3. Milk composition of sows at lactation day 0 and 14, when fed with diets supplemented with either DL-Methionine (DL-Met) or DL-2-hydroxy-4-methylthiobutanoic acid (OH-Met) at the requirements in TSAAs or above during the late gestation and lactation periods ${ }^{1}$.

\begin{tabular}{lccccc}
\hline \multicolumn{1}{c}{ Item } & CON & DL-Met & OH-Met & SEM & $p$-Value \\
\hline Lactation day 0 & & & & & \\
Fat, \% & 7.51 & 8.26 & 8.01 & 0.51 & 0.560 \\
Protein, \% & $6.32^{*,+}$ & $7.44^{+}$ & $7.92^{*}$ & 0.48 & 0.074 \\
Lactose, \% & $9.09^{\#}$ & 10.2 & $11.3^{\#}$ & 0.7 & 0.091 \\
Nonfat solid, \% & $16.9^{\mathrm{a},+}$ & $19.8^{\mathrm{b},+}$ & $21.1^{\mathrm{b}}$ & 1.2 & 0.049 \\
\hline Lactation day 14 & & & & \\
Fat, \% & 5.06 & 5.58 & 5.61 & 0.36 & 0.477 \\
Protein, \% & $4.48^{\mathrm{a}}$ & $5.22^{\mathrm{ab}}$ & $5.64^{\mathrm{b}}$ & 0.32 & 0.021 \\
Lactose, \% & $5.68^{\mathrm{a}}$ & $5.91^{\mathrm{a}}$ & $7.36^{\mathrm{b}}$ & 0.30 & $<0.01$ \\
$\quad$ Nonfat solid, \% & $10.7^{\mathrm{a}}$ & $11.7^{\mathrm{a}}$ & $14.7^{\mathrm{b}}$ & 0.6 & $<0.001$ \\
\hline
\end{tabular}

1 Values are means $\pm \mathrm{SE}, n=10$. ${ }^{\mathrm{a}-\mathrm{b}}$ Labeled means in a row with unlike superscript letters were significantly different by Tukey test $(p<0.05) .{ }^{*},{ }^{t},+,+$ Different: ${ }^{*} p=0.03{ }^{+} p=0.09 ;{ }^{*} p=0.03 ;^{+} p=0.10$. CON $=$ control diet; DL-Met $=$ CON supplemented with DL-Met at $25 \%$ above the total sulphur amino acids present in the control diet; $\mathrm{OH}-\mathrm{Met}=\mathrm{CON}$ supplemented with $\mathrm{OH}-$ Met at $25 \%$ above the total sulphur amino acids present in the control diet.

Compared with the CON, DL-Met, and OH-Met enhanced $(p \leq 0.05)$ the milk free amino acid concentrations of cystine, glutamic acid, isoleucine, leucine, lysine, methionine, threonine, tyrosine, $\alpha$-amino-n-butyric acid, $\beta$-amino-isobutyric acid, and taurine and decreased $(p \leq 0.05)$ ornithine and 3-methyl histidine concentrations at lactation d 0 and/or 14 (Table 4). Compared with the DL-Met group, the $\mathrm{OH}-\mathrm{Met}$ group had greater $(p \leq 0.05)$ milk free amino acid concentrations of cystine, isoleucine, leucine, lysine, methionine, tyrosine, and $\alpha$-amino-n-butyric acid but lower $(p \leq 0.05)$ ornithine and $\beta$-amino-isobutyric acid concentrations at lactation d 0 and/or 14 (Table 4 ). In contrast, the rest of the free amino acid concentrations in the milk of sows at the assayed time points were not affected by the dietary methionine supplementation (Supplementary Table S1).

Table 4. Effects of methionine supplementation on milk free amino acid concentrations of sows at lactation day 0 and $14^{1}$.

\begin{tabular}{|c|c|c|c|c|c|c|c|c|c|c|}
\hline \multirow[b]{2}{*}{ Compound, $\mu \mathrm{mol} / \mathrm{L}$} & \multicolumn{5}{|c|}{ Lactation Day 0} & \multicolumn{5}{|c|}{ Lactation Day 14} \\
\hline & $\mathrm{CON}$ & DL-Met & OH-Met & SEM & $p$ Value & $\mathrm{CON}$ & DL-Met & OH-Met & SEM & $p$-Value \\
\hline Cystine & $8.8^{c}$ & $13.4^{\mathrm{b}}$ & $22.7^{\mathrm{a}}$ & 2.0 & $<0.001$ & 12.4 & 15.2 & 14.8 & 1.5 & 0.386 \\
\hline Glutamic acid & 331 & 326 & 312 & 14 & 0.655 & $322^{\mathrm{a}}$ & $235^{b}$ & $232^{b}$ & 14 & $<0.001$ \\
\hline Isoleucine & $14.1^{\mathrm{c}}$ & $19.4^{\mathrm{b}}$ & $29.6^{\mathrm{a}}$ & 1.5 & $<0.001$ & $11.6^{\mathrm{b}}$ & $19.3^{\mathrm{a}}$ & $22.5^{\mathrm{a}}$ & 2.0 & 0.002 \\
\hline Leucine & 24.4 & 23.6 & 25.7 & 1.0 & 0.337 & $8.5^{c}$ & $18.3^{b}$ & $29.2^{\mathrm{a}}$ & 1.2 & $<0.001$ \\
\hline Lysine & $235^{c}$ & $412^{b}$ & $525^{a}$ & 25 & $<0.001$ & $36.7^{c}$ & $69.8^{\mathrm{b}}$ & $104^{\mathrm{a}}$ & 8.7 & $<0.001$ \\
\hline Methionine & $9.8^{c}$ & $36.0^{\mathrm{b}}$ & $54.3^{\mathrm{a}}$ & 2.1 & $<0.001$ & 23.6 & 21.8 & 20.7 & 2.3 & 0.662 \\
\hline Ornithine & $43.7^{\mathrm{a}}$ & $31.4^{\mathrm{b}}$ & $25.3^{c}$ & 1.7 & $<0.001$ & $15.8^{\mathrm{a}}$ & $13.7^{\mathrm{a}}$ & $9.3^{b}$ & 1.5 & 0.016 \\
\hline Taurine & $1465^{b}$ & $2157^{\mathrm{a}}$ & $2023^{a}$ & 51 & $<0.001$ & $857^{\mathrm{b}}$ & $1309^{a}$ & $1294^{\mathrm{a}}$ & 72 & $<0.001$ \\
\hline Threonine & $27.7^{b}$ & $39.7^{\mathrm{a}}$ & $41.6^{\mathrm{a}}$ & 1.7 & $<0.001$ & 11.0 & 11.0 & 12.5 & 1.2 & 0.601 \\
\hline Tyrosine & 15.8 & 16.3 & 16.4 & 0.7 & 0.746 & $14.5^{\mathrm{b}}$ & $18.3^{b}$ & $25.9^{\mathrm{a}}$ & 2.2 & 0.003 \\
\hline$\alpha$-amino-n-butyric acid & $2.6^{c}$ & $4.0^{\mathrm{b}}$ & $5.0^{\mathrm{a}}$ & 0.4 & $<0.001$ & $2.1^{\mathrm{c}}$ & $2.9^{b}$ & $3.7^{\mathrm{a}}$ & 0.2 & $<0.001$ \\
\hline$\beta$-amino-isobutyric acid & $18.0^{\mathrm{c}}$ & $57.0^{\mathrm{a}}$ & $43.6^{b}$ & 3.3 & $<0.001$ & 18.2 & 20.2 & 21.0 & 2.5 & 0.722 \\
\hline 3-methyl histidine & $1.8^{\mathrm{a}}$ & $0.2^{\mathrm{b}}$ & $0.3^{\mathrm{b}}$ & 0.2 & $<0.001$ & $1.2^{\mathrm{a}}$ & $0.7^{\mathrm{b}}$ & $0.5^{\mathrm{b}}$ & 0.1 & $<0.001$ \\
\hline
\end{tabular}




\subsection{Performance of Piglets after LPS Challenge from 35 to 63 Days Old}

The growth performance of the piglets was significantly affected by the LPS challenge, diet, or their interaction (Table 5). The 6 groups had similar standardized initial body weight of piglets. Compared with the saline injection, the LPS challenge decreased body weight gain $(p \leq 0.05)$ and feed intake $(p \leq 0.05)$ and tended to decrease the gain-to-feed ratio $(p \leq 0.10)$ of piglets from day 35 to 49 and from day 49 to 63 , respectively. Notably, the changes in the growth performance variables with the LPS challenge were attenuated $(p \leq 0.05)$ in piglets fed DL-Met and OH-Met compared to pigs fed the CON. Piglets fed increased levels of SAAs had higher body weight, body weight gain and gain-to-feed ratios than piglets fed the CON $(p<0.05)$ under the LPS challenge. The highest performance was obtained with OH-Met.

Table 5. Effects of methionine supplementation on performance of progeny after LPS challenge from 35 to 63 days old ${ }^{1}$.

\begin{tabular}{|c|c|c|c|c|c|c|c|c|c|c|}
\hline \multirow{2}{*}{ Item } & \multicolumn{3}{|c|}{ Saline } & \multicolumn{3}{|c|}{ LPS } & \multirow{2}{*}{ SEM } & \multicolumn{3}{|c|}{$p$-Value } \\
\hline & CON & DL-Met & OH-Met & CON & DL-Met & OH-Met & & LPS & Diet & $\begin{array}{l}\text { LPS } \times \\
\text { Diet }\end{array}$ \\
\hline $\begin{array}{l}\text { Body weight at day } 35, \mathrm{~kg} \\
\text { Day } 35-49\end{array}$ & 8.18 & 8.13 & 8.25 & 8.20 & 8.21 & 8.26 & 0.08 & 0.827 & 0.906 & 0.983 \\
\hline Body weight at day $49, \mathrm{~kg}$ & $11.8^{\mathrm{cd}}$ & $11.9^{\mathrm{cd}}$ & $12.1^{\mathrm{d}}$ & $10.3^{a}$ & $10.8^{\mathrm{ab}}$ & $11.1^{\mathrm{bc}}$ & 0.1 & $<0.001$ & 0.053 & 0.400 \\
\hline Daily weight gain, $\mathrm{kg}$ & $0.258^{\mathrm{bc}}$ & $0.267^{c}$ & $0.274^{\mathrm{c}}$ & $0.149^{\mathrm{a}}$ & $0.182^{\mathrm{a}}$ & $0.202^{\mathrm{ab}}$ & 0.013 & $<0.001$ & 0.040 & 0.369 \\
\hline Daily feed intake, kg & $0.398^{b c}$ & $0.413^{b c}$ & $0.429^{c}$ & $0.267^{\mathrm{a}}$ & $0.309^{a}$ & $0.338^{a b}$ & 0.019 & $<0.001$ & 0.047 & 0.577 \\
\hline Gain:feed & $0.645^{b}$ & $0.650^{\mathrm{b}}$ & $0.638^{\mathrm{b}}$ & $0.552^{\mathrm{a}}$ & $0.590^{\mathrm{ab}}$ & $0.598^{a b}$ & 0.017 & $<0.001$ & 0.379 & 0.303 \\
\hline \multicolumn{11}{|l|}{ Day 49-63 } \\
\hline Body weight at day $49, \mathrm{~kg}$ & $18.4^{\mathrm{c}}$ & $18.6^{\mathrm{c}}$ & $18.8^{\mathrm{c}}$ & $14.7^{\mathrm{a}}$ & $15.7^{\mathrm{ab}}$ & $16.1^{\mathrm{b}}$ & 0.3 & $<0.001$ & 0.042 & 0.224 \\
\hline Daily weight gain, $\mathrm{kg}$ & $0.474^{\mathrm{b}}$ & $0.483^{\mathrm{b}}$ & $0.476^{\mathrm{b}}$ & $0.316^{\mathrm{a}}$ & $0.349^{\mathrm{a}}$ & $0.360^{\mathrm{a}}$ & 0.020 & $<0.001$ & 0.460 & 0.594 \\
\hline Daily feed intake, $\mathrm{kg}$ & $0.843^{\mathrm{b}}$ & $0.855^{\mathrm{b}}$ & $0.834^{\mathrm{b}}$ & $0.715^{\mathrm{a}}$ & $0.676^{\mathrm{a}}$ & $0.683^{\mathrm{ab}}$ & 0.034 & $<0.001$ & 0.827 & 0.751 \\
\hline Gain:feed & $0.561^{\mathrm{b}}$ & $0.565^{\mathrm{b}}$ & $0.574^{\mathrm{b}}$ & $0.444^{\mathrm{a}}$ & $0.516^{\mathrm{b}}$ & $0.527^{b}$ & 0.016 & $<0.001$ & 0.014 & 0.058 \\
\hline \multicolumn{11}{|l|}{ Day 35-63 } \\
\hline Daily weight gain, $\mathrm{kg}$ & $0.366^{c}$ & $0.375^{c}$ & $0.375^{c}$ & $0.233^{\mathrm{a}}$ & $0.265^{\mathrm{ab}}$ & $0.281^{b}$ & 0.011 & $<0.001$ & 0.037 & 0.216 \\
\hline Daily feed intake, kg & $0.621^{b}$ & $0.631^{\mathrm{b}}$ & $0.634^{\mathrm{b}}$ & $0.491^{\mathrm{a}}$ & $0.493^{\mathrm{a}}$ & $0.510^{\mathrm{a}}$ & 0.015 & $<0.001$ & 0.625 & 0.797 \\
\hline Gain:feed & $0.589 \mathrm{bc}$ & $0.590^{b c}$ & $0.595^{\mathrm{bc}}$ & $0.474^{\mathrm{a}}$ & $0.539^{b}$ & $0.550^{b c}$ & 0.012 & $<0.001$ & 0.007 & 0.018 \\
\hline
\end{tabular}

\subsection{Plasma Biochemistry of Piglets after LPS Challenge}

The plasma biochemical variables of the piglets were significantly affected by the LPS challenge, diet, or their interaction (Table 6). Compared with the saline injection, the LPS challenge led to increased $(p \leq 0.05)$ activity of AST and concentration of TBIL and decreased $(p \leq 0.05)$ concentrations of ALB and TP in plasma at 4,12 , and/or $24 \mathrm{~h}$ post-LPS challenge. Meanwhile, the LPS challenge led to increased plasma levels of pro-inflammatory cytokines IL-1 $\beta$, IL- 6 and TNF-a at $4 \mathrm{~h}$ post-LPS challenge compared with the saline-treated group. Changes to most of these plasma biochemical variables due to the LPS challenge were alleviated in piglets fed DL-Met or OH-Met compared to pigs fed the CON. Piglets fed $\mathrm{OH}-$ Met exhibited similar values as the $\mathrm{CON}$ for some plasma biochemistry variables in comparison to piglets fed DL-Met at various time points after the LPS challenge. 
Table 6. Effect of methionine supplementation on plasma biochemistry of progeny after LPS challenge at $35 \mathrm{~d}$ old $^{1}$.

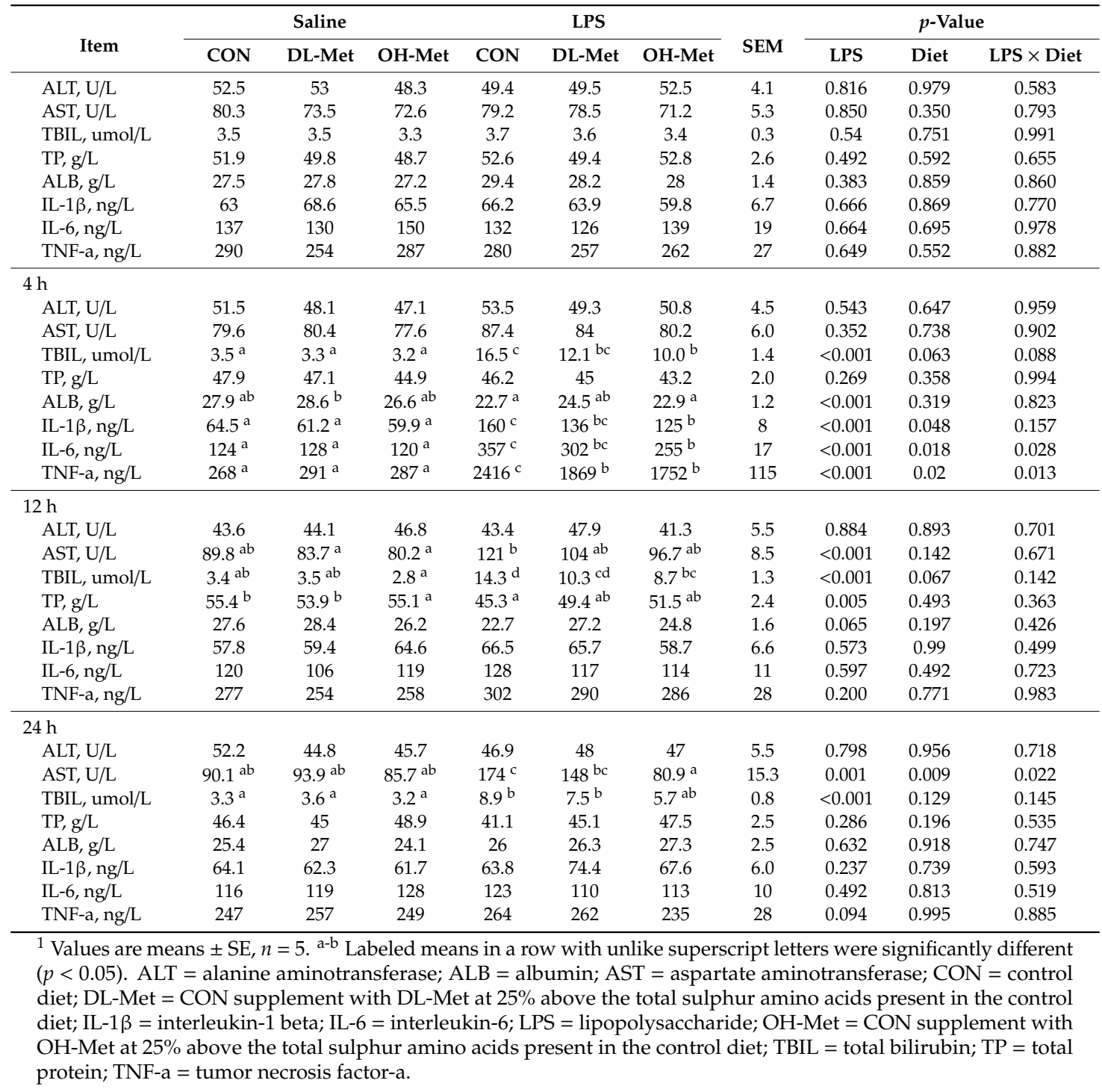

\subsection{Plasma Antioxidant Parameters of Piglets after LPS Challenge}

The plasma antioxidant variables of the piglets were significantly affected by the LPS challenge or diet (Table 7). Compared with the saline injection among pigs fed the CON, the LPS challenge led to decreased $(p \leq 0.05)$ activities of T-AOC (27.0-36.0\%) and GPX ( 15.7\%), and an increased $(p \leq 0.05)$ MDA (36.8-57.9\%) concentration in plasma at 12 and/or $24 \mathrm{~h}$ post-LPS challenge. Notably, changes to plasma T-AOC and GPX activities due to the LPS challenge were prevented $(p<0.05)$, but the MDA concentration was not alleviated in piglets fed DL-Met and OH-Met. 
Table 7. Effect of methionine supplementation on plasma antioxidant parameters of progeny after LPS challenge at $35 \mathrm{~d}$ old $^{1}$.

\begin{tabular}{|c|c|c|c|c|c|c|c|c|c|c|}
\hline \multirow{2}{*}{ Item } & \multicolumn{3}{|c|}{ Saline } & \multicolumn{3}{|c|}{ LPS } & \multirow{2}{*}{ SEM } & \multicolumn{3}{|c|}{$p$ Value } \\
\hline & $\mathrm{CON}$ & DL-Met & OH-Met & $\mathrm{CON}$ & DL-Met & OH-Met & & LPS & Diet & LPS $x$ Diet \\
\hline \multicolumn{11}{|l|}{$0 \mathrm{~h}$} \\
\hline GPX, U/mL & 591 & 622 & 585 & 594 & 619 & 576 & 30 & 0.904 & 0.394 & 0.979 \\
\hline T-AOC, U/L & 151 & 147 & 155 & 143 & 164 & 156 & 15 & 0.771 & 0.771 & 0.664 \\
\hline $\mathrm{GSH}, \mu \mathrm{mol} / \mathrm{L}$ & 23.9 & 27.8 & 27.4 & 24.6 & 26.8 & 26.3 & 2.1 & 0.796 & 0.300 & 0.895 \\
\hline GSSG, $\mu \mathrm{mol} / \mathrm{L}$ & 2.3 & 2.8 & 2.5 & 3.0 & 2.6 & 2.3 & 0.4 & 0.773 & 0.742 & 0.478 \\
\hline $\mathrm{MDA}, \mathrm{nmol} / \mathrm{L}$ & 1.6 & 1.5 & 1.6 & 1.7 & 1.6 & 1.9 & 0.2 & 0.321 & 0.490 & 0.877 \\
\hline \multicolumn{11}{|l|}{$4 \mathrm{~h}$} \\
\hline GPX, U/mL & 615 & 636 & 612 & 607 & 670 & 600 & 29 & 0.819 & 0.211 & 0.665 \\
\hline T-AOC, U/L & 164 & 158 & 172 & 156 & 146 & 157 & 15 & 0.337 & 0.701 & 0.974 \\
\hline $\mathrm{GSH}, \mu \mathrm{mol} / \mathrm{L}$ & 24.6 & 21.5 & 23.4 & 22.9 & 20.9 & 24.2 & 2.1 & 0.768 & 0.373 & 0.829 \\
\hline GSSG, $\mu \mathrm{mol} / \mathrm{L}$ & 1.3 & 1.4 & 1.1 & 1.5 & 1.2 & 1.2 & 0.3 & 0.891 & 0.698 & 0.782 \\
\hline $\mathrm{MDA}, \mathrm{nmol} / \mathrm{L}$ & 1.8 & 1.8 & 2 & 1.6 & 1.9 & 1.9 & 0.2 & 0.748 & 0.523 & 0.838 \\
\hline \multicolumn{11}{|l|}{$12 \mathrm{~h}$} \\
\hline GPX, U/mL & 499 & 505 & 510 & 471 & 466 & 482 & 24 & 0.114 & 0.867 & 0.963 \\
\hline T-AOC, U/L & $145^{\mathrm{a}}$ & $134^{\mathrm{a}}$ & $130^{a}$ & $92.8^{b}$ & $113^{\mathrm{ab}}$ & $130^{a}$ & 13 & 0.03 & 0.695 & 0.140 \\
\hline $\mathrm{GSH}, \mu \mathrm{mol} / \mathrm{L}$ & 13.3 & 15.0 & 12.9 & 12.0 & 14.8 & 13.0 & 2.1 & 0.785 & 0.515 & 0.934 \\
\hline $\mathrm{GSSG}, \mu \mathrm{mol} / \mathrm{L}$ & 2.5 & 2.7 & 2.4 & 2.6 & 2.6 & 2.3 & 0.4 & 0.782 & 0.803 & 1.000 \\
\hline $\mathrm{MDA}, \mathrm{nmol} / \mathrm{L}$ & $1.8^{\mathrm{a}}$ & $2.2^{\mathrm{ab}}$ & $1.8^{\mathrm{b}}$ & $2.7^{\mathrm{ab}}$ & $2.9^{\mathrm{a}}$ & $2.6^{\mathrm{ab}}$ & 0.2 & $<0.001$ & 0.234 & 0.914 \\
\hline \multicolumn{11}{|l|}{$24 \mathrm{~h}$} \\
\hline GPX, U/mL & $458^{\mathrm{a}}$ & $473^{a}$ & $467^{\mathrm{a}}$ & $386^{\mathrm{b}}$ & $421^{\mathrm{ab}}$ & $426^{a b}$ & 24 & 0.008 & 0.479 & 0.803 \\
\hline T-AOC, U/L & $124^{\mathrm{a}}$ & $120^{a}$ & $131^{a}$ & $90.5^{b}$ & $108^{\mathrm{ab}}$ & $109^{a b}$ & 13 & 0.04 & 0.627 & 0.700 \\
\hline $\mathrm{GSH}, \mu \mathrm{mol} / \mathrm{L}$ & 10 & 10.8 & 9.8 & 7.1 & 9.5 & 10.3 & 1.5 & 0.334 & 0.493 & 0.547 \\
\hline $\mathrm{GSSG}, \mu \mathrm{mol} / \mathrm{L}$ & 2.5 & 2.0 & 1.9 & 2.3 & 2.0 & 2.1 & 0.3 & 0.826 & 0.370 & 0.787 \\
\hline $\mathrm{MDA}, \mathrm{nmol} / \mathrm{L}$ & $2.0^{\mathrm{b}}$ & $1.9^{\mathrm{b}}$ & $1.9^{\mathrm{b}}$ & $2.9^{a}$ & $3.0^{\mathrm{a}}$ & $2.6^{\mathrm{a}}$ & 0.3 & $<0.001$ & 0.771 & 0.820 \\
\hline
\end{tabular}

${ }^{1}$ Values are means $\pm \mathrm{SE}, n=5$. ${ }^{\mathrm{a}-\mathrm{b}}$ Labeled means in a row with unlike superscript letters were significantly different $(p<0.05)$. DL-Met $=$ CON supplement with DL-Met at $25 \%$ above the total sulphur amino acids present in the control diet; GPX = glutathione peroxidase; GSH = glutathione; GSSG = glutathione disulfide; $\mathrm{LPS}=$ lipopolysaccharide; MDA $=$ malondialdehyde; $\mathrm{OH}-\mathrm{Met}=\mathrm{CON}$ supplement with $\mathrm{OH}-\mathrm{Met}$ at $25 \%$ above the total sulphur amino acids present in the control diet; T-AOC = total antioxidant capacity.

\section{Discussion}

The present study shows that maternal and neonatal methionine supplementation, particularly in the form of $\mathrm{OH}-\mathrm{Met}$, during late gestation, lactation, and postweaning, can improve the performance of sows and their progeny. Dietary supplementation of both DL-Met and OH-Met did not affect body weight, backfat thickness, feed intake and litter size at birth for the sows, but OH-Met supplementation reduced the loss of body weight and backfat thickness of sows during lactation. A previous study also showed that dietary supplementation of DL-Met and OH-Met during lactation did not affect the body weight and backfat thickness of sows, but the loss of body weight and backfat during lactation was not calculated [15]. Because loss of body weight and backfat during lactation reduces subsequent reproductive performance [28,29], the present study offers the first evidence that dietary supplementation of $\mathrm{OH}-\mathrm{Met}$ during later gestation and lactation benefits body energy metabolism and can potentially improve the reproduction of sows. Likewise, dietary supplementation of DL-Met and(or) OH-Met increased the body weight gain of piglets during day 0-7 and day 7-14. These outcomes were similar to a previous study, in which dietary supplementation of $\mathrm{OH}-\mathrm{Met}$ during lactation increased the body weight of piglets at day 14, while DL-Met supplementation did not affect piglet body weight [15]. This discrepancy could be attributed to the different dietary methionine supplementation period. Indeed, dietary supplementation of both DL-Met and OH-Met increased milk protein, lactose, and/or nonfat solid at lactation day 0 , but only $\mathrm{OH}$-Met supplementation increased milk protein, lactose, and nonfat solids at lactation d 14; these results are similar to those of previous studies performed in cows and sows $[15,30,31]$. Supplementation of methionine increased milk quality and may be associated with the mechanisms: (1) methionine supplementation increased the level of arterial concentrations of methionine, which improved the amino acid supply to the mammary gland for milk synthesis [31]; (2) the HMTBA potential increase the blood flow may also contribute to increased milk production [15]; (3) increasing milk lactose and protein levels positively correlates with 
milk yield [32]. These data indicate that maternal dietary methionine supplementation might improve the body weights of piglets.

Thirteen free amino acids present in milk were affected by maternal dietary methionine supplementation. Among them, five essential amino acids (isoleucine, leucine, lysine, methionine, threonine) and a nonessential amino acid (tyrosine) are used by cells to synthesize proteins and play important roles in the activation of protein biosynthesis [33]. Thus, increasing these amino acids in the milk by maternal dietary DL-Met or OH-Met supplementation could contribute to increasing the body weight gain of piglets. The increased concentrations of these amino acids were associated with a decrease of glutamic acid in milk in the DL-Met and OH-Met groups. The lower milk concentration of glutamic acid in the DL-Met and OH-Met groups was the result of the lower levels of glutamic acid in sows' plasma (data not shown). Glutamic acid is known to be the major fuel of the gut, which means that a higher proportion of glutamic acid was metabolized by the intestine in the first-pass [34]. Therefore, the increase in glutamic acid catabolism might have reduced the catabolism of dietary-essential amino acids as energy substrates for the intestinal mucosa, thus explaining the increased concentrations of amino acids in sows' plasma and milk, as shown in multicatheterized piglets [34]. However, lower milk glutamic acid levels at lactation day 14 in the DL-Met and OH-Met groups might also compromise the benefits of the improved milk quality on growth performance for piglets. Indeed, the body weight gain of piglets during day 14-21 did not increase in the DL-Met and OH-Met groups in the current study. Nevertheless, the mechanism of Met increases glutamic acid catabolism in the gut and needs to be further explored. In addition, 3-methyl histidine, a muscular proteolysis marker [35], was reduced in the milk of sows in the DL-Met and OH-Met groups, which indicated less muscle wasting in sows of the DL-Met and OH-Met groups relative to those of the CON group. These results might potentially explain the lower losses of body weight and backfat thickness of sows during lactation in the dietary $\mathrm{OH}-\mathrm{Met}$ supplementation group. However, since dietary DL-Met supplementation had the same effects on milk glutamic acid and 3-methyl histidine as OH-Met without significantly affecting body weight and backfat thickness of sows during lactation, this finding would need to be further explored in additional studies.

Maternal dietary DL-Met and/or OH-Met supplementation also increased free amino acids in milk that were associated with redox control (cystine and taurine), which might enhance the ability of piglets to cope with stress [36]. Additionally, maternal dietary methionine supplementation increased free amino acids in milk that play roles in the nonribosomal peptide synthases ( $\alpha$-amino-n-butyric acid) and cell metabolism ( $\beta$-amino-isobutyric acid) and decreased free amino acids in milk that play roles in the urea cycle (ornithine) [1,37]. The actual contribution of these alterations to amino acids in milk on the performance of sows and piglets still need to be further studied.

Another novel finding in the current study was that methionine, particularly in the form of $\mathrm{OH}-\mathrm{Met}$, alleviated LPS-induced adverse effects in piglets. The LPS challenge reduced body weight gain, feed intake and feed utilization efficiency throughout the study in piglets, in accordance with earlier studies [38]. Strikingly, changes to these growth performance variables due to the LPS challenge were alleviated by dietary OH-Met supplementation, while only the changes to the gain-to-feed ratio during d 49-63 due to the LPS challenge were mitigated by dietary DL-Met supplementation. Moreover, the LPS challenge induced hepatic injury and inflammatory reactions that included increased AST activity and TBIL concentration and decreased ALB and TP concentrations in plasma at 4, 12 and/or $24 \mathrm{~h}$ post-LPS challenge; the plasma levels of pro-inflammatory cytokines IL- $1 \beta$, IL- 6 and TNF-a were also increased at $4 \mathrm{~h}$ post-LPS challenge. These outcomes were in accordance with previous studies [39-42]. Interestingly, methionine supplementation attenuated the plasma biochemistry changes induced by the LPS challenge, and piglets fed $\mathrm{OH}-$ Met displayed a stronger ability to mitigate these plasma biochemistry changes relative to piglets fed DL-Met. Furthermore, consistent with previous studies $[18,43]$, the piglets challenged by LPS in this experiment experienced oxidative stress, as indicated by the reduction of antioxidant capacity (GPX and T-AOC) and increased lipid peroxidation (MDA), whereas dietary supplementation of both DL-Met and OH-Met prevented these changes in 
GPX and T-AOC. Meanwhile, piglets in the DL-Met and OH-Met groups fed milk and diets with higher cystine, taurine and methionine experienced enhanced antioxidant capacity [15,16]. Taken together, these outcomes agree with previous studies, which reported that LPS challenges reduce piglets' growth performance in association with inflammation and oxidative stress. However, dietary methionine supplementation, especially in the form of OH-Met, showed protective actions against LPS-impaired growth performance in piglets, which was associated with an enhancement of immune function and antioxidant capacities.

\section{Conclusions}

Maternal and neonatal methionine supplementation during late gestation, lactation and postweaning improved the performance of sows and their progeny. This was mainly associated with improved milk quality, along with increased essential (isoleucine, leucine, lysine, methionine, threonine) and reduction-oxidative control (cystine and taurine) amino acids and decreased energy (glutamic acid) and muscular proteolysis markers (3-methyl histidine) amino acids in milk. Moreover, prolonged supplementation of methionine in the postweaning diet of the progeny improved their ability to counteract LPS-induced negative effects, which may be due to the enhancement of anti-inflammation and antioxidant capacities of piglets. Finally, better results were obtained with dietary supplementation of OH-Met in comparison to DL-Met for most of these variables, which indicates that OH-Met might be a better methionine source than DL-Met for pig production. This novel finding indicated that the current methionine requirement from NRC (2012) may be underestimated and could have meaningful impacts on swine nutrition and health.

Supplementary Materials: The following are available online at http://www.mdpi.com/2076-2615/9/12/1048/s1.

Author Contributions: L.-H.S., D.B.-A., and L.-B.M. designed the research; Y.Z., B.-Y.X., L.Z., L.-Y.Z., D.-S.Q., and S.-J.Z., conducted the experiments; L.-H.S. and D.B.-A. wrote the paper. D.B.-A. and J.J. conducted the statistical analyses. L.-H.S. had the primary responsibility for the final content. All authors read and approved the final manuscript.

Funding: The present study was supported in part by the fundamental research funds for the Central Universities (2662019PY059 and 2662018PY030); the National Key Research and Development Program of China, Projects 2018YFD0500600 and 2016YFD0501207;; Innovation Group of Hubei Natural Science Foundation (2018CFA020); and a research grant (16MEI536) by Adisseo France S.A.S., 10, Place du Général de Gaulle, 92160 Antony, France.

Conflicts of Interest: Author disclosures: Y.Z., B.Y.X., L.Z., L.Y.Z., D.S.Q., S.J.Z., L.B.M., and L.H.S., no conflicts of interest. D.B.A. and J.J. are employees of Adisseo.

\section{References}

1. Wu, G. Amino acids: Metabolism, functions, and nutrition. Amino Acids 2009, 37, 1-17. [CrossRef]

2. Remus, A.; Peres, F.M.; Hauschild, L.; Andretta, I.; Kipper, M.; Gobi, J.P.; Pomar, C. Exploratorystudy on the utilization of different dietary methionine sources and methionine to lysine ratio for growing-finishing pigs. Livest. Sci. 2015, 181, 96-102. [CrossRef]

3. Brede, A.; Wecke, C.; Liebert, F. Does the Optimal Dietary Methionine to Cysteine Ratio in Diets for Growing Chickens Respond to High Inclusion Rates of Insect Meal from Hermetia illucens? Animals 2018, 8, 187. [CrossRef] [PubMed]

4. Ghoreyshi, S.M.; Omri, B.; Chalghoumi, R.; Bouyeh, M.; Seidavi, A.; Dadashbeiki, M.; Lucarini, M.; Durazzo, A.; Hoven, R.; Santini, A. Effects of Dietary Supplementation of L-Carnitine and Excess Lysine-Methionine on Growth Performance, Carcass Characteristics, and Immunity Markers of Broiler Chicken. Animals 2019, 9, 608. [CrossRef] [PubMed]

5. Donato, D.C.; Sakomura, N.K.; Silva, E.P.; Troni, A.R.; Vargas, L.; Guagnoni, M.A.; Meda, B. Manipulation of dietary methionine+cysteine and threonine in broilers significantly decreases environmental nitrogen excretion. Animal 2016, 10, 903-910. [CrossRef] [PubMed]

6. Conde-Aguilera, J.A.; Floc'h, N.L.; Huërou-Luron, I.L.; Mercier, Y.; Tesseraud, S.; Lefaucheur, L.; Milgen, J. Splanchnic tissues respond differently when piglets are offered a diet $30 \%$ deficient in total sulfur amino acid for 10 days. Eur. J. Nutr. 2016, 55, 2209-2219. [CrossRef] 
7. Baker, D.H. Comparative species utilization and toxicity of sulfur amino acids. J. Nutr. 2006, 136, 1670-1675. [CrossRef]

8. Ball, R.O.; Courtney-Martin, G.; Pencharz, P.B. The in vivo sparing of methionine by cysteine insulfur amino acid requirements in animal models and adult humans. J. Nutr. 2006, 136, 1682-1693. [CrossRef]

9. Niculescu, M.D.; Zeisel, S.H. Diet, methyl donors and DNA methylation: Interactions between dietary folate, methionine and choline. J. Nutr. 2002, 132, 2333-2335. [CrossRef]

10. Giguére, A.; Girard, C.L.; Matte, J.J. Methionine, folic acid and vitamin B12 in growing-finishing pigs: Impact on growth performance and meat quality. Arch. Anim. Nutr. 2008, 62, 193-206. [CrossRef]

11. Gasparino, E.; Del Vesco, A.P.; Khatlab, A.S.; Zancanela, V.; Grieser, D.O.; Silva, S.C.C. Effects of methionine hydroxy analogue supplementation on the expression of antioxidant-related genes of acute heat stress-exposed broilers. Animal 2018, 12, 931-939. [CrossRef]

12. Zhao, L.; Zhang, N.Y.; Pan, Y.X.; Zhu, L.Y.; Batonon-Alavo, D.I.; Ma, L.B.; Khalil, M.M.; Qi, D.S.; Sun, L.H. Efficacy of 2-hydroxy-4-Methylthio-butanoic acid compared to DL-Methionine on growth performance, carcass traits, feather growth, and redox status of Cherry Valley ducks. Poult. Sci. 2018, 97, 3166-3175. [CrossRef]

13. Vazquez-Anon, M.; Bertin, G.; Mercier, Y.; Reznik, G.; Roberton, J.L. Review of the chemistry, metabolism, and dose response of two supplemental methionine sources and the implications in their relative bioefficacy. World Poultry Sci. J. 2017, 73, 725-736. [CrossRef]

14. Martín-Venegas, R.; Rodríguez-Lagunas, M.J.; Geraert, P.A.; Ferrer, R. Monocarboxylate transporter 1 mediates DL-2-Hydroxy-(4-methylthio)butanoic acid transport across the apical membrane of Caco-2 cell monolayers. J. Nutr. 2007, 137, 49-54. [CrossRef] [PubMed]

15. Zhang, X.; Li, H.; Liu, G.; Wan, H.; Mercier, Y.; Wu, C.; Wu, X.; Che, L.; Lin, Y.; Xu, S.; et al. Differences in plasma metabolomics between sows fed DL-methionine and its hydroxy analogue reveal a strong association of milk composition and neonatal growth with maternal methionine nutrition. Br. J. Nutr. 2015, 113, 585-595. [CrossRef]

16. Li, H.; Wan, H.; Mercier, Y.; Zhang, X.; Wu, C.; Wu, X.; Tang, L.; Che, L.; Lin, Y.; Xu, S.; et al. Changes in plasma amino acid profiles, growth performance and intestinal antioxidant capacity of piglets following increased consumption of methionine as its hydroxy analogue. Br. J. Nutr. 2014, 112, 855-867. [CrossRef]

17. Goswami, P.S.; Friendship, R.M.; Gyles, C.L.; Poppe, C.; Boerlin, P. Preliminary investigations of the distribution of Escherichia coli $\mathrm{O} 149$ in sows, piglets, and their environment. Can. J. Vet. Res. 2011, 75, 57-60.

18. Hou, X.; Zhang, J.; Ahmad, H.; Zhang, H.; Xu, Z.; Wang, T. Evaluation of antioxidant activities of ampelopsin and its protective effect in lipopolysaccharide-induced oxidative stress piglets. PLoS ONE 2014, 9, e108314. [CrossRef]

19. Klasing, K.C. Nutrition and the immune system. Br. Poult. Sci. 2007, 48, 525-537. [CrossRef]

20. Rakhshandeh, A.; Htoo, J.K.; Karrow, N.; Miller, S.P.; Lange, C.F. Impact of immune system stimulation on the ileal nutrient digestibility and utilisation of methionine plus cysteine intake for whole-body protein deposition in growing pigs. Br. J. Nutr. 2014, 111, 101-110. [CrossRef]

21. Zhang, L.B.; Guo, Y.M. Effects of liquid DL-2-hydroxy-4-methylthio butanoic acid on growth performance and immune responses in broiler chickens. Poult. Sci. 2008, 87, 1370-1376. [CrossRef]

22. Sun, L.H.; Li, J.G.; Zhao, H.; Shi, J.; Huang, J.Q.; Wang, K.N.; Xia, X.J.; Li, L.; Lei, X.G. Porcine serum can be biofortified with selenium to inhibit proliferation of three types of human cancer cells. J. Nutr. 2013, 143, 1115-1122. [CrossRef]

23. Pi, D.; Liu, Y.; Shi, H.; Li, S.; Odle, J.; Lin, X.; Zhu, H.; Chen, F.; Hou, Y.; Leng, W. Dietary supplementation of aspartate enhances intestinal integrity and energy status in weanling piglets after lipopolysaccharide challenge. J. Nutr. Biochem. 2014, 25, 456-462. [CrossRef]

24. Mudd, A.T.; Alexander, L.S.; Johnson, S.K.; Getty, C.M.; Malysheva, O.V.; Caudill, M.A.; Dilger, R.N. Perinatal Dietary Choline Deficiency in Sows Influences Concentrations of Choline Metabolites, Fatty Acids, and Amino Acids in Milk throughout Lactation. J. Nutr. 2016, 146, 2216-2223. [CrossRef] [PubMed]

25. Gao, X.; Xiao, Z.H.; Liu, M.; Zhang, N.Y.; Khalil, M.M.; Gu, C.Q.; Qi, D.S.; Sun, L.H. Dietary Silymarin Supplementation Alleviates Zearalenone-Induced Hepatotoxicity and Reproductive Toxicity in Rats. J. Nutr. 2018, 148, 1209-1216. [CrossRef] [PubMed]

26. Zhao, L.; Feng, Y.; Deng, J.; Zhang, N.Y.; Zhang, W.P.; Liu, X.L.; Rajput, S.A.; Qi, D.S.; Sun, L.H. Selenium Deficiency Aggravates Aflatoxin B1-Induced Immunotoxicity in Chick Spleen by Regulating 6 Selenoprotein Genes and Redox/Inflammation/Apoptotic Signaling. J. Nutr. 2019, 149, 894-901. [CrossRef] 
27. Zhao, L.; Sun, L.H.; Huang, J.Q.; Briens, M.; Qi, D.S.; Xu, S.W.; Lei, X.G. A Novel Organic Selenium Compound Exerts Unique Regulation of Selenium Speciation, Selenogenome, and Selenoproteins in Broiler Chicks. J. Nutr. 2017, 147, 789-797. [CrossRef]

28. Houde, A.A.; Methot, S.; Murphy, B.D.; Bordignon, V.; Palin, M.F. Relationships between backfat thickness and reproductive efficiency of sows: A two-year trial involving two commercial herds fixing backfat thickness at breeding. Can. J. Vet. Res. 2010, 90, 429-436. [CrossRef]

29. Kim, J.S.; Yang, X.; Baidoo, S.K. Relationship between Body Weight of Primiparous Sows during Late Gestation and Subsequent Reproductive Efficiency over Six Parities. Asian-Australas. J. Anim. Sci. 2016, 29, 768-774. [CrossRef]

30. Piepenbrink, M.S.; Marr, A.L.; Waldron, M.R.; Butler, W.R.; Overton, T.R.; Vázquez-Añón, M.; Holt, M.D. Feeding 2-hydroxy-4-(methylthio)-butanoic acid to periparturient dairy cows improves milk production but not hepatic metabolism. J. Dairy Sci. 2004, 87, 1071-1084. [CrossRef]

31. Wang, C.; Liu, H.Y.; Wang, Y.M.; Yang, Z.Q.; Liu, J.X.; Wu, Y.M.; Yan, T.; Ye, H.W. Effects of dietary supplementation of methionine and lysine on milk production and nitrogen utilization in dairy cows. $J$. Dairy Sci. 2010, 93, 3661-3670. [CrossRef] [PubMed]

32. Shahbazkia, H.R.; Aminlari, M.; Tavasoli, A.; Mohamadnia, A.R.; Cravador, A. Associations among milk production traits and glycosylated haemoglobin in dairy cattle; importance of lactose synthesis potential. Vet. Res. Commun. 2010, 34, 1-9. [CrossRef] [PubMed]

33. Appuhamy, J.A.; Knoebel, N.A.; Nayananjalie, W.A.; Escobar, J.; Hanigan, M.D. Isoleucine and leucine independently regulate mTOR signaling and protein synthesis in MAC-T cells and bovine mammary tissue slices. J. Nutr. 2012, 142, 484-491. [CrossRef] [PubMed]

34. Fang, Z.; Yao, K.; Zhang, X.; Zhao, S.; Sun, Z.; Tian, G.; Yu, B.; Lin, Y.; Zhu, B.; Jia, G.; et al. Nutrition and health relevant regulation of intestinal sulfur amino acid metabolism. Amino Acids 2010, 39, 633-640. [CrossRef] [PubMed]

35. Ballard, F.J.; Tomas, F.M. 3-Methylhistidine as a measure of skeletal muscle protein breakdown in human subjects: The case for its continued use. Clin. Sci. 1983, 65, 209-215. [CrossRef]

36. Moeser, A.J.; Pohl, C.S.; Rajput, M. Weaning stress and gastrointestinal barrier development: Implications for lifelong gut health in pigs. Anim. Nut. 2017, 3, 313-321. [CrossRef]

37. Roberts, L.D.; Boström, P.; O'Sullivan, J.F.; Schinzel, R.T.; Lewis, G.D.; Dejam, A.; Lee, Y.K.; Palma, M.J.; Calhoun, S.; Georgiadi, A.; et al. $\beta$-Aminoisobutyric acid induces browning of white fat and hepatic $\beta$-oxidation and is inversely correlated with cardiometabolic risk factors. Cell Metab. 2014, 19, 96-108. [CrossRef]

38. Waititu, S.M.; Yin, F.; Patterson, R.; Rodriguez-Lecompte, J.C.; Nyachoti, C.M. Short-term effect of supplemental yeast extract without or with feed enzymes on growth performance, immune status and gut structure of weaned pigs challenged with Escherichia coli lipopolysaccharide. J. Anim. Sci. Biotechnol. 2016, 7, 64. [CrossRef]

39. Leng, W.; Liu, Y.; Shi, H.; Li, S.; Zhu, H.; Pi, D.; Hou, Y.; Gong, J. Aspartate alleviates liver injury and regulates mRNA expressions of TLR4 and NOD signaling-related genes in weaned pigs after lipopolysaccharide challenge. J. Nutr. Biochem. 2014, 25, 592-599. [CrossRef]

40. Hou, X.; Wang, T.; Ahmad, H.; Xu, Z.W. Ameliorative effect of ampelopsin on LPS-induced acute phase response in piglets. J. Funct. Food 2017, 35, 489-498. [CrossRef]

41. Azad, M.A.K.; Bin, P.; Liu, G.; Fang, J.; Li, T.; Yin, Y. Effects of different methionine levels on offspring piglets during late gestation and lactation. Food Funct. 2018, 9, 5843-5854. [CrossRef] [PubMed]

42. Li, N.Y.; Sun, Z.J.; Ansari, A.R.; Cui, L.; Hu, Y.F.; Li, Z.W.; Briens, M.; Kai, L.; Sun, L.H.; Karrow, N.A.; et al. Impact of Maternal Selenium Supplementation from Late Gestation and Lactation on Piglet Immune Function. Biol. Trace Elem. Res. 2019, in press. [CrossRef] [PubMed]

43. Li, Q.; Liu, Y.; Che, Z.; Zhu, H.; Meng, G.; Hou, Y.; Ding, B.; Yin, Y.; Chen, F. Dietary L-arginine supplementation alleviates liver injury caused by Escherichia coli LPS in weaned pigs. Innate Immun. 2012, 18, 804-814. [CrossRef] [PubMed]

(C) 2019 by the authors. Licensee MDPI, Basel, Switzerland. This article is an open access article distributed under the terms and conditions of the Creative Commons Attribution (CC BY) license (http://creativecommons.org/licenses/by/4.0/). 